\title{
PRODUÇÃO DE RESENHA ACADÊMICA: UMA ABORDAGEM DOS GÊNEROS DO DISCURSO
}

\section{ACADEMIC REVIEW WRITING AN APPROACH TO SPEECH GENRES}

\author{
Maria Inês Batista Campos* \\ Universidade São Paulo, São Paulo, SP, Brasil \\ Maria das Graças Soares Rodrigues** \\ Universidade Federal do Rio Grande do Norte, Natal, RN, Brasil
}

\begin{abstract}
Resumo: A escrita acadêmica recebeu muitos estudos desde o final da década de 1970, mas há alguns gêneros acadêmicos que trazem dificuldades aos estudantes universitários, como a resenha. 0 objetivo do artigo é discutir essa produção de graduandos em Letras, a partir da concepção bakhtiniana de gênero discursivos e de ponto de vista, segundo Rabatel (2015, 2016, 2016a, 2017, 2018), 0 que significa tratar as resenhas dentro de um contexto de circulação, produccão e recepcão. Na primeira parte, apresentaremos os pressupostos teóricos que norteiam essa discussão, particularmente, a noção de resenha como gênero discurisivo. Na segunda parte, tendo em vista considerarmos a categoria do ponto de vista (PDV) como intrínsecca à organizaçãa linguística, textual, discursiva e enunciativa da resenha, focalizaremos algumas noç̃oes teóricas seguidas de análises de dados, que ancorarão nossa reflexão. A análise de uma resenha publicada em revista acadêmica de graduaç̃ó revelou que o LI/El se engajiou com o objeto de discurso, ao construir o ponto de vista (PDV), certamente, para influenciar os interlocutores, acerca da obra resenhada. Em suma, a natureza do propósito comunicativo do gênero discursivo resenha leva o Ll/El a assumir um PDV favorável ou nõo.
\end{abstract}

Palavras-chave: gêneros discursivos; escrita acadêmica; resenha acadêmica; ponto de vista; engajamento.

Abstract: Academic writing has received many studies since the late 1970s, but there are some speech genres that bring difficulties to college students, such as the review. The objective of the article is to discuss this production of undergraduate students of Languages and Linguistics, from the Bakhtinian conception of discursive genres and point of view, according to Rabatel $(2015,2016$, 2016a, 2017, 2018), which means to treat the reviews within a context of circulation, production and reception. In the first part, we will introduce the theoretical assumptions that guide this discussion, particularly the notion of review as a discursive genre. In the second part, considering the category of the point of view (POV) as intrinsic to the linguistic, textual, discursive and enunciative organization of the academic review, we will focus on some theoretical notions followed by data analysis, which will anchor our reflection. The analysis of an academic review published in an undergraduate academic journal revealed that $L I$ / El engaged with the object of discourse, when constructing the point of view (POV), certainly, to influence the interlocutors about the work reviewed. In short, the

* Professora doutora da Universidade São Paulo - USP, São Paulo, Brasil; maricamp@usp.br

* Professora doutora da Universidade Federal do Rio Grande do Norte - UFRN, Natal, RN, Brasil; gracasrodrigues@gmail.com 
Linha D'Água (Online), São Paulo, v. 31, n. 1, p. 221-237, jan.-abril 2018

nature of the communicative purpose of the discursive genre review leads $L I$ / El to assume a favorable POV or not.

Keywords: Speech Genre; Academic Writing; Critical Review, Point of View; Engajament.

\section{Introdução}

A riqueza e a diversidade dos gêneros do discurso são infinitas porque são inesgotáveis as possibilidades da multifacetada atividade humana e porque em cada campo dessa atividade vem sendo elaborado todo um repertório de gêneros do discurso, que cresce e se diferencia à medida que tal campo se desenvolve e ganha complexidade.

BAKHTIN, 2016, p.12.

\section{Considerações iniciais}

A produção de textos acadêmicos no ensino de graduação faz parte das exigências avaliativas do curso de Letras. Entre os vários textos produzidos nessa esfera de atividade, encontra-se a resenha crítica. É um gênero discursivo que tem o propósito de apresentar e comentar uma obra publicada, um filme, uma exposição de arte, desempenhando um papel fundamental ao leitor, que por meio do texto resumido, toma conhecimento da produção intelectual, e a partir dos dados e apreciações do resenhador pode decidir pela leitura ou não do texto.

Esse gênero circula também em alguns periódicos acadêmicos e nosso interesse é investigar o processo de escrita de alunos da graduação dentro da esfera periodística. Uma consulta realizada em revistas científicas da área de Letras e Linguística, disponíveis online, permitiu-nos identificar quatro títulos dirigidos a graduandos de Letras. Entre eles, destacamos: Ao pé da letra, Universidade Federal de Pernambuco, criada em 1998 pelo departamento de Letras para valorizar a escrita acadêmica dos estudantes; Revele, Revista virtual dos estudantes de Letras, graduação e pós-graduação da Universidade Federal de Minas Gerais; Arcádia, Revista de literatura e crítica literária da Unicamp; Fronteira digital, Unimat, Campus Pontes Lacerda, Mato Grosso. Neste artigo, analisaremos duas resenhas, 
Linha D'Água (Online), São Paulo, v. 31, n. 1, p. 221-237, jan.-abril 2018

publicadas na revista Ao pé da letra, n. 18/2, de jun. a dez. 2016, por ser a única que traz essa rubrica no seu sumário.

Entre os anos de 2004 e 2010, alguns pesquisadores brasileiros organizaram livros com práticas teórico-metodológicas com o objetivo de articular leitura e produção de resenha. São volumes dirigidos a estudantes universitários interessados em elaborar textos, usando recursos linguísticos-discursivos na articulação de ideias. Entre as publicações, o livro Resenha, de Machado, Lousada, Abreu-Tardelli, começa com a diferença entre resumo e resenha. Abordam o gênero textual resenha sob a perspectiva teórica do Interacionismo sociodiscursivo.

As autoras apresentam a ação de resenhar relacionada à atividade de leitura, de interpretação e de sumarização. E trazem um quadro com aspectos fundamentais para a produção de uma resenha: "autor, função social dele, destinatário real, imagem que o autor tem que ter de seu destinatário, tema/objeto, locais e/ou veículos onde o texto provavelmente circulará, momento de produção e objetivo do autor do texto" (MACHADO; LOUSADA; TARDELLI, 2004, p. 87).

Em seguida, focam as informações em torno do contexto e do tema do trabalho resenhado, a fim de mobilizar conteúdos de outras obras, o que permite ao resenhador estabelecer comparações entre textos diferentes e fazer seus comentários. As pesquisadoras também destacam o uso dos organizadores textuais "que melhor expressam as relações que queremos estabelecer" (2004, p. 115). E indicam a importância de argumentos convincentes para que os leitores possam dialogar com o ponto de vista expresso pelo autor da resenha. $\mathrm{O}$ objetivo da resenha, portanto, é divulgar uma obra recém-lançada da área de conhecimento, recomendando ou não a leitura do texto.

No livro Produção textual na universidade (2010), de D. Motta-Roth e G.R. Hendges, há um detalhado capítulo sobre o gênero "Resenha". Ao apresentar o objetivo desse texto usado pela academia, as autoras apontam dois aspectos: "o resenhador basicamente descreve e avalia uma dada obra a partir de um ponto de vista informado pelo conhecimento produzido anteriormente sobre aquele tema. Seus comentários devem se conectar com a área do saber em que a obra foi produzida ou com outras disciplinas relevantes para o livro em questão" (2010, p. 28). 
Linha D'Água (Online), São Paulo, v. 31, n. 1, p. 221-237, jan.-abril 2018

Para as autoras, a produção da resenha estrutura-se em quatro etapas: apresentação; descrição, avaliação, (não) recomendação do livro. Ainda no capítulo elas comparam resenhas de linguística, economia e química, assinalando a variabilidade dos textos em cada disciplina e os diferentes diálogos que se estabelecem com o público-alvo. A avaliação do autor da resenha passa por uma relação com os valores constituídos pela comunidade acadêmica.

\section{A resenha como gênero do discurso na perspectiva de Bakhtin e do Círculo}

A concepção enunciativa de "texto" ou "enunciado" é chave para a compreensão de "gênero do discurso" e está discutida em vários ensaios da obra de Bakhtin e o Círculo. "Texto" é entendido como enunciado concreto, como um acontecimento social, uma interação verbal entre interlocutores, nunca é tratado como orações isoladas. Há teorias linguísticas que tratam o texto na sua dimensão exclusivamente linguística, mas na perspectiva bakhtiniana esse conceito adquire densidade no confronto entre, ao menos, dois interlocutores, situados histórica e socialmente.

A noção de "texto" pressupõe a compreensão do funcionamento da comunicação a partir de uma cadeia discursiva em que cada elo tem fronteiras materiais definidas e o texto constrói sentido tão-somente na interação com outros textos precedentes e subsequentes. Bakhtin considera que o texto não se limita exclusivamente a uma análise linguística dos fenômenos puramente da língua, mas trata da relação com os horizontes sociais em que ele se inscreve:

[...] Um enunciado isolado e concreto sempre é dado num contexto cultural e semântico-axiológico (científico, artístico, político, etc.) ou no contexto de uma situação isolada da vida privada; apenas nesses contextos o enunciado isolado é vivo e compreensível: ele é verdadeiro ou falso, belo ou disforme, sincero ou malicioso, franco, cínico, autoritário e assim por diante. Não há enunciados neutros” (BAKHTIN: 1998, p. 46).

Essa abordagem teórica permite compreender a materialidade linguística e discursiva num movimento dialógico com a situação concreta, no seu contexto 
Linha D'Água (Online), São Paulo, v. 31, n. 1, p. 221-237, jan.-abril 2018

social, político, cultural, ideológico. No ensaio escrito na década de 1960, Bakhtin refere-se a texto numa perspectiva teórico-metodológico das ciências humanas:

Se concebe o texto no sentido amplo como qualquer conjunto coerente de signos, a ciência das artes (a musicologia, a teoria e a história das artes plásticas) opera com textos (obras de arte). São pensamentos sobre pensamentos, vivências das vivências, palavras sobre palavras, textos sobre textos. Nisto reside a diferença essencial entre as nossas disciplinas (humanas) e naturais (sobre a natureza) [...], embora aqui não haja fronteiras absolutas, impenetráveis (BAKHTIN: 2016, p. 71-72).

A relação texto/ enunciado aprofunda-se no ensaio Os gêneros do discurso (1952-1953), na seção intitulada "O enunciado como unidade da comunicação discursiva”. Partindo dos diferentes campos/ esferas da atividade humana em que os modos de comunicação se realizam, Bakhtin explica que "cada enunciado particular é individual, mas cada campo de utilização da língua elabora seus tipos relativamente estáveis de enunciados, os quais denominamos gêneros do discurso". (BAKHTIN: 2016, p. 12). É importante ressaltar que a relativa estabilidade do gênero se caracteriza por apresentarem três aspectos: construção composicional, conteúdo temático e estilo, dimensões de natureza dialógica. Quanto à construção composicional, trata da estrutura particular de cada texto pertencente ao gênero; o conteúdo temático é a relação entre o enunciado e o sentido, salientando que não é sinônimo de assunto, mas da forma de dar acabamento ao objeto de sentido; quanto ao estilo dos gêneros, Bakhtin define como "a seleção dos recursos lexicais, fraseológicos e gramaticais da língua".

Bakhtin amplia o conceito de gênero do discurso, estabelecendo relações entre as práticas sociais e as atuações humanas, uma vez que são entendidas de maneira dialógica. Assim, a linguagem se organiza de modo diferente dependendo do campo/esfera de atuação específica. As características dos gêneros do discurso estão relacionadas a finalidade, funcionamento e especificidade de cada campo/ esfera da atividade humana.

Em cada campo existem e são empregados gêneros que correspondem às condições específicas de dado campo; é a esses gêneros que correspondem determinados estilos. Uma função (científica, técnica, publicística, oficial, cotidiana) e certas

CAMPOS, M. I. B., RODRIGUES, M. G. S. Produção de resenha acadêmica: uma 
Linha D'Água (Online), São Paulo, v. 31, n. 1, p. 221-237, jan.-abril 2018

condições de comunicação discursiva, específicas de cada campo, geram determinados gêneros, isto é, determinados tipos de enunciados estilísticos, temáticos e composicionais relativamente estáveis (BAKHTIN: 2016, p. 18).

Cada gênero do discurso tem seu próprio funcionamento, uma vez que depende da esfera a que está relacionado, cada texto é uma resposta a enunciados anteriores e uma antecipação da resposta ativa dos destinatários. No gênero resenha, por exemplo, o autor recupera a obra publicada e deixa espaço para o diálogo com o leitor do seu texto.

Conhecer e dominar os gêneros acadêmicos como a resenha crítica é uma prática cada vez mais importante no espaço universitário para que se possa produzir textos com clareza. $\mathrm{O}$ uso de processos de sumarização e de estratégias de substituição permite uma escrita com flexibilidade e sem seguir regras rígidas e homogêneas de resumo. Bakhtin argumenta o quanto o conhecimento do gênero do discurso permite ao sujeito se expressar bem na sua própria língua:

Muitas pessoas que dominam magnificamente uma língua sentem amiúde total impotência em alguns campos da comunicação, justo porque não dominam na prática as formas do gênero desses campos. [...]. Aqui não se trata de pobreza vocabular nem de estilo tomado de maneira abstrata; tudo se resume a uma inabilidade para dominar o repertório dos gêneros da conversa mundana. [...] Quanto mais dominamos os gêneros, maior é a desenvoltura com que os empregamos e mais plena e nitidamente descobrimos neles a nossa individualidade [...] em suma, tanto mais plena é a forma com que realizamos o nosso livre projeto de discurso. (BAKHTIN: 2016, p. 41)

Ao analisarmos as resenhas publicadas na Revista Ao pé da letra, o primeiro critério foi identificá-las como gêneros produzidos por estudantes de Letras (campo/esfera de circulação); o segundo critério foi estabelecer o recorte temporal: o ano de 2016 com o propósito de apontar os participantes e, finalizar, com a análise textual, envolvendo as circunstâncias enunciativas. 
Linha D'Água (Online), São Paulo, v. 31, n. 1, p. 221-237, jan.-abril 2018

\section{0 ponto de vista em resenha acadêmica: uma abordagem enunciativa}

A caracterização e discussão sobre o gênero discursivo resenha, conforme a primeira parte deste artigo, autorizam-nos a considerar a categoria do ponto de vista (PDV) como intrínseca à sua organização linguística, textual, discursiva e enunciativa. Nessa direção, focalizaremos algumas noções teóricas seguidas de análises de dados, que ancorarão nossa reflexão, a fim de responder à questão: como se estrutura o PDV no gênero discursivo resenha?

Adam (2011, p. 110) trata indistintamente o ponto de vista (PDV) e a responsabilidade enunciativa (RE), quando nos diz que "a responsabilidade enunciativa ou ponto de vista (PDV) permite dar conta do desdobramento polifônico próprio à ironia" [...]. Por seu turno, Rabatel (2017, p. 45) explica que "o PDV é comunicado [...] pela instância primeira que, em seu discurso (independentemente do plano de enunciação adotado), coloca-se no lugar daquele que ela imita o PDV". A instância primeira é o que o autor nomeia de locutor enunciador primeiro (L1/E1), ou seja, é o autor do texto falado ou escrito. Em nosso corpus, a instância primeira é o autor da resenha.

O PDV reflete a opinião que o enunciador tem acerca de um determinado objeto do discurso. Para tanto, recorre ao léxico e a procedimentos de referenciação, entre outros mecanismos. Evocamos Rabatel quando postula a seguinte definição de PDV:

[...] defino como ponto de vista (PDV), em linguística, todo enunciado que predica informações sobre não importa que objeto do discurso, dando não apenas informações sobre o objeto (relativos à sua denotação), mas também, sobre a forma como o enunciador observa o objeto, expressando, assim, um PDV. O objeto do PDV pode ser um indivíduo, um coletivo, um anônimo, e pode exprimir PDV singulares ou coletivos, originais ou estereotipados. (RABATEL, 2017: p. 43)

O exemplo, a seguir, é o parágrafo que inicia a resenha 01 escolhida para análise, o qual ilustra a definição transcrita ipsis litteris. 
Linha D'Água (Online), São Paulo, v. 31 , n. 1, p. 221-237, jan.-abril 2018

\section{Exemplo 1}

Obra repleta de exemplos, com ricas referências a clássicos da literatura nacional mundial, passando por artigos, editoriais, reportagens e notícias de importantes jornais e revistas, além de textos publicitários e peças de teatro, o livro Argumentação, de José Luiz Fiorin (2015), é um achado para quem se interessa pelo tema.

A escolha lexical que constitui sintagmas nominais está marcada pela subjetividade, conforme evidenciam:

Obra repleta de exemplos [...]

ricas referências $[\ldots]$

artigos, editoriais, reportagens e notícias de importantes jornais e revistas [...]

O locutor enunciador primeiro (L1/E1) predica acerca do objeto de discurso anunciado no título da resenha, que é, naturalmente, o título do livro que ele se propôs a resenhar. Podemos observar a presença de adjetivos valorativos, como é o caso de "repleta", "rica" e "importante”. Essas construções iniciais já apontam para o interlocutor a posição do L1/E1 acerca da obra.

Ademais, convém sublinhar a construção do enunciado em forma diversa da ordem canônica SVO (sujeito / verbo / objetivo). Certamente, se o enunciado fosse "O livro Argumentação, de José Luiz Fiorin (2015), é um achado para quem se interessa pelo tema, $\varnothing$ obra repleta de exemplos"[...], teríamos a ocorrência de elipse de uma forma verbal antes do sintagma nominal complexo "Obra repleta de exemplos", como, por exemplo, poderia ser "e'". Isso nos autoriza inferir que essa elipse da forma verbal "é", que manteria o paralelismo com o enunciado "é um achado para quem se interessa pelo tema", aponta que essa forma verbal elíptica estaria em lugar de "acho", ou de "considero", entre outras, i.e., trata-se de um dispositivo enunciativo designado de "embreagem actancial", na perspectiva de Greimas (apud FLORES et al., (2009, p. 93) em que uma pessoa verbal é usada no lugar de outra, ou seja, a 3a. pessoa do singular elíptica teria um valor de 1a. pessoa do singular, no caso específico, veiculando um sentido opinativo. 
Linha D'Água (Online), São Paulo, v. 31, n. 1, p. 221-237, jan.-abril 2018

A postura enunciativa do L1/E1 é ratificada ao longo da resenha, conforme mostram os exemplos a seguir:

\section{Exemplo 2}

O autor, que tem dois cursos de pós-doutorado e centenas de trabalhos publicados sobre esse e outros temas, explora os mecanismos discursivos relativos à persuasão, enumerando tipos de argumentos, trazendo reflexões valiosas, acompanhadas de trechos de textos que contribuem, sobremaneira, para o entendimento de cada um deles e tornam o material uma fonte de consulta indispensável, não apenas para quem trabalha com a palavra, mas, também, para quem quer fazer um melhor uso dela em qualquer contexto.

trazendo reflexões valiosas $[\ldots]$

tornam o material uma fonte de consulta indispensável [...]

O movimento discursivo é marcado por um PDV representado, tendo em vista a percepção do L1/E1 se construir via um processo de predicação que se torna objeto de uma expansão ao longo do texto. Evocamos Rabatel (2016, p. 134), quando explicita: "se um PDV implica percepções representadas, isso passa por uma sucessão de predicados que estão em relação temática com a percepção inicial predicada." Há recorrência de sintagmas nominais marcados pela presença de unidades lexicais subjetivas, como é o caso de "valiosas" e “indispensável”, entre inúmeras outras.

O figura 1 apresenta uma classificação proposta por Kerbrat-Orecchioni (2006, p. 94) acerca da distinção entre várias categorias de adjetivos subjetivos. 
Linha D'Água (Online), São Paulo, v. 31, n. 1, p. 221-237, jan.-abril 2018

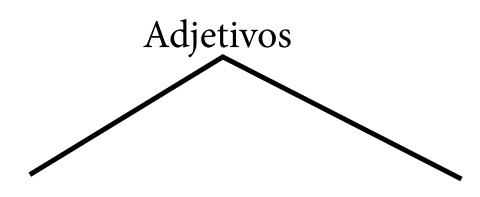

Objetivos. Ex.:

Solteiro/casado adjetivos de cor macho / fêmea

d)

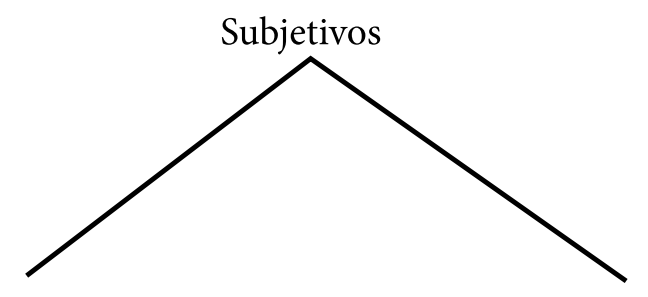

Afetivos

Ex.

a) $\left\{\begin{array}{l}\text { pungente } \\ \text { engraçado } \\ \text { patético }\end{array}\right.$

b) $\left\{\begin{array}{l}\text { Não axioló } \\ \text { grande } \\ \text { longe } \\ \text { quente } \\ \text { numeroso }\end{array}\right.$

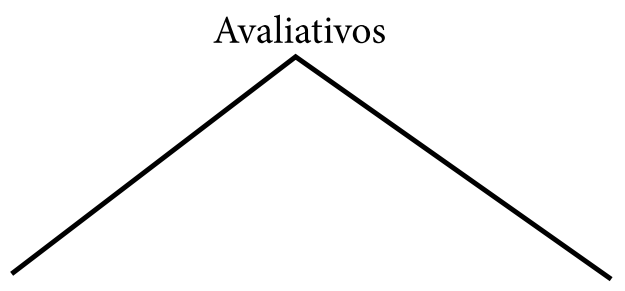

Axiológicos

c) $\left\{\begin{array}{l}\text { bom } \\ \text { bonito } \\ \text { bem }\end{array}\right.$

Figura 1: Distinção entre categorias de adjetivos subjetivos

Fonte: KERBRAT-ORECCHIONI: 2006, p. 94.

Para concluir a reflexão acerca do PDV, orientado por uma visada argumentativa do L1/E1 que busca seduzir o interlocutor, aludimos a outro dispositivo enunciativo, que é a tentativa de apagamento enunciativo. Para tanto, transcrevemos, a seguir, o último parágrafo da resenha:

\section{Exemplo 3}

Trata-se de um livro objetivo, que vai direto ao ponto, com profundidade teórica, mas com aporte prático, sem divagações que, muitas vezes, dificultam a leitura, especialmente de quem venha a se interessar por ele como manual de consulta e não como fonte de pesquisa teórico-metodológica para fins profissionais. 
Linha D'Água (Online), São Paulo, v. 31, n. 1, p. 221-237, jan.-abril 2018

Subjaz ao exemplo 3 que o L1/E1 reitera em sua conclusão, a recomendação da obra, conforme mostra o enunciado que inicia o parágrafo - "Trata-se de um livro objetivo, que vai direto ao ponto, com profundidade"[...].

$\mathrm{O}$ estilo concernente às formas verbais, em $3 \mathrm{a}$. pessoa do singular, usadas pelo L1/E1 para desenvolver seu PDV sobre o livro resenhado, não apaga o sujeito enunciador, uma vez que a escolha lexical marcada pela subjetividade demonstra seu engajamento em relação ao conteúdo proposicional dos enunciados. A propósito, lembramos Charaudeau (1992, p. 650) que nomeia de "simulacro enunciativo" "um 'jogo' que joga o sujeito falante, como se lhe fosse possível não ter ponto de vista, mas desaparecer completamente do ato de enunciação, e deixar falar o discurso por si próprio".

Assim, esse "simulacro enunciativo" ou essa estratégia de apagamento enunciativo, que tenta jogar o L1/E1 para mascarar seu PDV, ou mesmo tentar se distanciar da assunção da responsabilidade enunciativa acerca de outro discurso, ou seja, no caso em reflexão, sobre o livro, objeto da resenha, ela é inócua, uma vez que a posição enunciativa do L1/E1 está expressa por meio da referenciação, tendo em vista que, enquanto interlocutores, conseguimos estabelecer sentidos, através do léxico em uso, em contexto, enfim, semiotizado, que promove a continuidade temática.

O corpus evidencia o que Desclès (2016, p. 83), em sua proposta de um cartão semântico intitulado "Operações enunciativas de assunção de responsabilidade enunciativa por um enunciador", nomeia de "simples enunciação: assunção da responsabilidade enunciativa de uma relação predicativa", o que corresponde à posição do "eu" que se engaja em relação a um referencial enunciativo que ele propõe ao coenunciador em situações de diálogo.

Ainda que nosso corpus seja da modalidade escrita, permitimo-nos a fazer essa analogia, haja vista o L1/E1 da resenha se dirigir a interlocutores que espera conseguir influenciar com o PDV que põe em circulação sobre determinado objeto do discurso. No caso da resenha em análise, há uma representação discursiva que se mantém, enquanto coerência argumentativa interna ao texto e também em relação ao real extralinguístico, uma vez que o autor do livro, objeto da resenha, é um pesquisador renomado, reconhecido por suas inumeráveis contribuições aos estudos linguísticos, de modo especial, no que concerne à enunciação e à análise do discurso. 
Linha D'Água (Online), São Paulo, v. 31 , n. 1, p. 221-237, jan.-abril 2018

\section{Considerações finais}

Para cumprirmos o objetivo que orientou esse artigo, procedemos a uma discussão sobre os gêneros discursivos, na perspectiva bakhtiniana, assim como fizemos uma caracterização do gênero discursivos resenha. $\mathrm{Na}$ sequência, fizemos uma análise para ilustrar a construção do PDV pelo L1/E1. A análise revelou que o L1/E1 se engaja e assume a responsabilidade enunciativa pelo conteúdo proposicional dos enunciados, através dos processos de referenciação e de predicação, o que permitiu a continuidade temática. O engajamento do L1/E1 com o objeto de discurso mostrou-se de forma valorativa, buscando influenciar o interlocutor.

Por fim, consideramos que a escolha lexical foi determinante para que circulasse a visada argumentativa de recomendação da obra resenhada.

\section{Referências}

ADAM, Jean-Michel. A linguística textual: introdução à análise textual dos discursos, 2. ed. São Paulo: Cortez, 2011.

Introduction. In. ADAM, Jean-Michel (Dir.). Faire texte: frontières textuelles et opérations de textualisation. Besançon: Presses Universitaires de Franche-Comté, 2015, p.11-33.

BAKHTIN, M. Mikhail. O problema do conteúdo, do material e da forma na criação literária. In: Questôes de literatura e de estética: A teoria do romance. Trad. Aurora F. Bernadini e outros. São Paulo: Hucitec, 1998, p. 13-70.

O problema do texto na linguística, na filologia e em outras ciências humanas. In: Estética da criação verbal. Tradução de Paulo Bezerra. São Paulo: Martins Fontes, 2016, p. 71-110.

. Os gêneros do discurso. Organização, tradução, posfácio e notas Paulo Bezerra. São Paulo: Editora 34, 2016.

CHARAUDEAU, Patrick. Grammaire du sens et de l'expression. Paris: Hachette, 1992.

CAMPOS, M. I. B., RODRIGUES, M. G. S. Produção de resenha acadêmica: uma 
Linha D'Água (Online), São Paulo, v. 31, n. 1, p. 221-237, jan.-abril 2018

DESCLÉS, Jean-Pierre. Opérations et opérateurs énonciatifs. In. COLAS-BLAISE, Marion; PERRIN, Laurent; TORE, Gian Maria (Dirs.) L'énonciation aujourd'bui: un concept clé des sciences du langage. Limoges: Lambert-Lucas, 2016, p.69-88.

ESTUPIÑÁN, Mireya Cisneros. Como elaborar trabajos de grado. 2. ed. Bogotá: Ecoe Ediciones, 2012.

FLORES, Valdir do Nascimento et al. (Orgs). Dicionário de linguística da enunciação. São Paulo: Contexto, 2009.

FRANÇOIS, Frédéric. Quelques points de vue sur les points de vue. In. CARCASSONNE, Marie; CUNHA, Dóris; DONAHUE, Christiane; FRANÇOIS, Frédéric; RABATEL, Alain. Points de vue sur le point de vue. Limoges: Lambert-Lucas, 2015, p.7-76.

KERBRAT-ORECCHIONI, Catherine. L'énonciation. Paris: Armand Colin, 2006.

KLEIN, IRENE (Coord.) El taller del escritor universitario. Buenos Aires: Prometeo Libros, 2007.

MACHADO, Anna Rachel; LOUSADA, Eliane; ABREU-TARDELLI (Orgs.) Resenha. São Paulo: Parábola, 2004.

MOTTA-ROTH, Désirée; HENDGES, Graciela Rabuske. Produção textual na universidade. São Paulo: Parábola, 2010.

SIMON, Justine. Effacement énonciatif et effet de non-prise encharge des discours représentés dans deux hyperstructures du Magazine Citato. In. DENDALE, Patrick; COLTIER, Danielle. La prise en charge énonciative: études théoriques et empiriques. Bruxelles: De Boeck / Duculot, 2011, p. 143-162.

PLANTIN, Christian. Dictionnaire de l'argumentation: une introduction aux études d'argumentation. Lyon: ENS Éditions, 2016.

RABATEL, Alain. Postures énonciatives, variable générique et stratégies depositionnement. In. ARGEMULLER, Johannes; PHILIPPE, Gilles. Analyses du discours et dispositifs d'énonciation: autour des travaux de Dominique Maingueneau. Limoges: Lambert-Lucas, 2015, p. 124-135.

CAMPOS, M. I. B., RODRIGUES, M. G. S. Produção de resenha acadêmica: uma 
Linha D'Água (Online), São Paulo, v. 31, n. 1, p. 221-237, jan.-abril 2018

Homo narrans: por uma abordagem enunciativa e interacionista da narrativa. Tradução Maria das Graças Soares Rodrigues, Luis Passeggi e João Gomes da Silva Neto. São Paulo: Cortez, 2016.

Diversité des points de vue et mobilité emphatique. In. COLAS-BLAISE, Marion; PERRIN, Laurent; TORE, Gian Maria. L'énonciation aujourd'bui: un concept clé des sciences du langage. Limoges: Lambert-Lucas, 2016a, p. 135-150.

Pour une lecture linguistique et critique des médias: empathie, éthique, point(s) de vue. Limoges: Lambert-Lucas, 2017.

Pour une reconception de l'argumentation à la lumière de la dimension argumentative des discours. 2018. (no prelo)

RODRIGUES, Maria das Graças Soares; PASSEGGI, Luis. Émotions, argumentation et points de vue dans l'affaire Nafissatou Diallo contre Dominique Strauss-Kahn. Une analyse textuelle et discursive de chroniques de la Folha de São Paulo. In. RABATEL, Alain; MONTE, Michèle; RODRIGUES, Maria das Graças Soares. Comment les médias parlent des émotions. L'affaire Nafissatou Diallo contre Dominique Strauss-Kahn. Limoges: Lambert-Lucas, 2015, p. 291-305.

RODRIGUES, Maria das Graças Soares. Linguística textual e responsabilidade enunciativa. In. CAPISTRANO Jr. Rivaldo; LINS, Maria da Penha Pereira; ELIAS, Vanda (Orgs.). Linguistica textual: diálogos interdisciplinares. São Paulo: Labrador, 2017, p. 299-316.

SCHEEPERS, Caroline. L'argumentation écrite. Bruxelles: De Boeck Duculot, 2013.

Recebido: 2/02/2018.

Aprovado: 28/02/2018.

CAMPOS, M. I. B., RODRIGUES, M. G. S. Produção de resenha acadêmica: uma 
Linha D'Água (Online), São Paulo, v. 31, n. 1, p. 221-237, jan.-abril 2018

\section{Anexo}

Resenha elaborada sob a orientação da Profa. Dra. Laurênia Souto Sales (UFPB) como parte das atividades da disciplina Metodologia do trabalho científico do curso de Licenciatura em Letras - Língua Inglesa, da UFPB Virtual.

FIORIN, José Luiz. Argumentação. São Paulo: Editora Contexto, 2015.

Fernando Alves de Oliveira (UFPB)

Obra repleta de exemplos, com ricas referências a clássicos da literatura nacional e mundial, passando por artigos, editoriais, reportagens e notícias de importantes jornais e revistas, além de textos publicitários e peças de teatro, o livro Argumentação, de José Luiz Fiorin (2015), é um achado para quem se interessa pelo tema. $\mathrm{O}$ autor, que tem dois cursos de pós-doutorado e centenas de trabalhos publicados sobre esse e outros temas, explora os mecanismos discursivos relativos à persuasão, enumerando tipos de argumentos, trazendo reflexões valiosas, acompanhadas de trechos de textos que contribuem, sobremaneira, para o entendimento de cada um deles e tornam o material uma fonte de consulta indispensável, não apenas para quem trabalha com a palavra, mas, também, para quem quer fazer um melhor uso dela em qualquer contexto. Com declarada influência da Teoria da Argumentação na Língua (TAL), de Oswald Ducrot e Jean Claude Anscombre, Fiorin (2015) faz uma discussão que permite ao leitor entender de retórica e argumentação. Essas noções são essenciais para a compreensão do modelo de estudo discursivo da língua lançado pelos dois autores franceses e, consequentemente, para melhor leitura do livro, que é dividido em três grandes partes: problemas gerais de argumentação, os argumentos e a organização do discurso. Desde os mais estudados nas aulas de Língua Portuguesa no ensino básico - como exemplificação, analogia, causa e efeito e autoridade - até outros como perguntas capciosas, autofagia e retorsão, dilema, terceiro excluído, paradoxo, ironia, silêncio e sacrifício, a obra esmiúça os vários tipos de argumentos, tudo isso aliado a uma revisão teórica explicada com cuidado e ilustrada com textos de diversos gêneros.

CAMPOS, M. I. B., RODRIGUES, M. G. S. Produção de resenha acadêmica: uma 
Linha D'Água (Online), São Paulo, v. 31, n. 1, p. 221-237, jan.-abril 2018

A capa do livro traz o afresco "Cícero denuncia Catilina", de Cesare Maccari, que representa uma reunião do Senado romano, na Cúria Hostília, para discutir acusações de conspiração do assassinato do cônsul Marco Túlio Cícero por Lucio Catilina, deixando clara a intensa influência da tradição clássica dos estudos argumentativos, fundamento das pesquisas que embasaram o texto. Argumentação, referenciando o Órganon e a Retórica, de Aristóteles, o De oratore e as Acadêmicas, de Cícero, além dos sermões de Padre Antônio Vieira, com o objetivo de confrontar visões, já que, com base em Ducrot e Anscombre, Fiorin (2015) afirma ser necessária a incorporação de um componente semântico para entendimento das proposições, elemento não privilegiado nas noções clássicas de argumentatividade e persuasão. Os estudos sobre os três tipos de inferência são a base do capítulo 2 . Nele, são debatidas questões cruciais como processo de fundamentação de recepção ou rejeição de formas argumentativas a partir da relação entre as sentenças; a maneira como os significados determinam conclusões e como os usos que se fazem da linguagem influenciam as trocas verbais.

No terceiro capítulo, o foco são as formas de raciocínio, operações que contribuem para o estabelecimento de conclusões como a dedução, cujo principal tipo é o silogismo, recurso estudado à exaustão, através de vários exemplos. Há, ainda, a indução e a analogia. No último capítulo da primeira parte, um dos mais interessantes, o tema são os fatores que ajudam o interlocutor a completar, com sucesso, o processo de argumentação, a saber: o enunciador ou orador e seu éthos (caráter), o enunciatário ou auditório e seu páthos (estado de espírito) e o próprio discurso (logos). Sobre esse último, o autor propõe uma discussão envolvendo argumentação e linguagem, que toca em pontos interessantes como ambiguidade e vagueza, discursos pretensamente objetivos, imparciais e neutros, linguagem politicamente correta, dentre outros temas que mobilizam discussões em rodas de estudo ou conversa.

A segunda parte do livro é a maior e mais detalhada. Lista dezenas de tipos de argumentos, divididos em quase lógicos; fundamentados na estrutura da realidade e fundamentados na estrutura do real, tratando, ainda, sobre a dissociação de noções e trazendo, também, outras técnicas argumentativas, cada uma com várias subdivisões, todas repletas de exemplos os mais variados. Um trabalho de fôlego que transforma o livro em um verdadeiro manual. No campo dos quase lógicos, estão aqueles que 
Linha D'Água (Online), São Paulo, v. 31, n. 1, p. 221-237, jan.-abril 2018

"lembram a estrutura de um raciocínio lógico, mas suas conclusões não são logicamente necessárias" (FIORIN, 2015, p. 116), englobando a tautologia, a definição, a transitividade, reciprocidade, o dilema, a comparação, dentre outros.

Os argumentos fundamentados na realidade têm relação com o mundo objetivo, a exemplo dos fatos, das falas de autoridade, dos que estabelecem causalidade e sucessão. Já os fundamentados na estrutura do real têm uma diferença: são considerados modos de organização da realidade e, dentre eles, estão exemplo, ilustração e antimodelo. A importante ideia de dissociação de noções é explicada a seguir, abrangendo essência/aparência e distinção, mas mencionando, também, as ligações entre objetivo/causa, teoria/prática, linguagem/pensamento, dentre outros pares frequentemente associados com o objetivo de formular argumentos. Uma contribuição deveras importante para profissionais que trabalham com a formação de leitores, inclusive servindo como excelente material para aulas de Língua Portuguesa em todos os níveis de escolaridade.

$\mathrm{Na}$ terceira parte do livro, o autor trata de outras técnicas argumentativas, discorre sobre o recurso aos valores (balizas morais da sociedade); aos lugares-comuns; aos implícitos; argumentos do espantalho (defender ponto de vista contrário a uma ideia que sequer foi apresentada), dentre outros. Falando sobre a organização do discurso, Fiorin (2015) destaca que há intrínseca relação com a construção/seleção dos argumentos e a forma como eles são encadeados no enunciado. Para ilustrar sua afirmação, retoma a Retórica, de Aristóteles e estuda, em detalhes, Sermão da Epifania, de Padre Antônio Vieira, ambos tomados como referência no que se refere à organização interna do discurso. Ao final, discute teorias do discurso e argumentação. Trata-se de um livro objetivo, que vai direto ao ponto, com profundidade teórica, mas com aporte prático, sem divagações que, muitas vezes, dificultam a leitura, especialmente de quem venha a se interessar por ele como manual de consulta e não como fonte de pesquisa teórico-metodológica para fins profissionais.

REVISTA AO PÉ DA LETRA - VOLUME 18.2 - 2016 | 140-141

Disponível em: <http://revistaaopedaletra.net/volumes/ volume-18-2-revista-ao-pe-da-letra/ $>$.

Acesso em: 23 nov. 2017

CAMPOS, M. I. B., RODRIGUES, M. G. S. Produção de resenha acadêmica: uma 